\title{
Scientific aid to Brazil is strangled by red tape
}

\section{The cost of importing donated equipment can be more than its original purchase price.}

Sir - Young Brazilian scientists not only have to pay high prices for equipment, as reported in your News story "High prices of supplies drain cash from poorer nations' labs" (Nature 428, 453; 2004), they receive little funding from government agencies, and encounter obstacles if they obtain international support. For instance, when a Brazilian institution has valuable equipment donated by laboratories in the developed world, getting the equipment through customs is a surreal experience. Not only does it require tremendous amounts of paperwork; in some cases release from customs can take more than a year, during which time storage is charged. Consequently, the cost of importing scientific equipment to
Brazil is often higher than the cost of the equipment itself in the developed world.

What is at stake here is more than specific items of equipment. This situation risks undermining the creation in Brazil of new research groups led by young scientists, trained abroad in the most upto-date techniques. In the United States, for example, the Pew Latin American Fellows Program awards junior biomedical scientists US\$35,000 at the end of their US postdoctoral training, to help establish laboratories back home. The benefits of such schemes are many, but they will falter without a different policy towards foreign scientific trade and donations.

The nomination of a new minister of science and technology, Eduardo Campos, offers some hope. Although state and municipal institutions are also responsible for delays in importing goods, the possibility of reform is mostly in federal hands. President Luis Inacio Lula's administration, which was elected with a mandate for change, should give immediate attention to these matters. Stevens Kastrup Rehen

Department of Molecular Biology, The Scripps Research Institute, 10550 North Torrey Pines Road, ICND118, La Jolla, California 92037, USA Signed on behalf of:

A. Muotri, A.-M. Landeira-Fernandez, J.-G. Abreu, M. da Silva

Almeida, M. Guimarães, R. Mohana-Borges, S. Ribeiro.

Full addresses are available from the corresponding author.

\section{Ugly truths should not stop Pakistan's reforms}

Sir - Your Editorial about science reform and alleged sales of nuclear technology to Iran, "Good and bad in Pakistan" (Nature 427, 379; 2004), mentions both good and bad, but stops short of citing the 'ugly'. Yet there are two ugly truths involved.

The first is the state of international politics, which keeps shifting its goalposts, and accordingly either ignores the obvious or sometimes searches for the obscure. Witness, for example, the newly discovered activities of Abdul Qadeer Khan, Pakistan's former chief nuclear scientist. It beggars belief that a solo scientist would be capable of exchanging nuclear know-how for missiles without the active participation of the army, and hence the government. It is getting clearer now that key players in the international community, including the United States, knew a lot about these activities but chose to remain quiet (see, for example, the International Herald Tribune of 21 April 2003; www.iht.com/ articles/93839.html).

The second ugly truth is the fact that Pakistan never signed the nuclear nonproliferation treaty, and therefore the International Atomic Energy Agency can do very little about Pakistan's proliferation activities in any case.

Your Editorial was perhaps too quick in predicting repercussions from these events on science in Pakistan, which has been making progress recently.

It is more probable than not that President Musharraf, in order to gain the confidence of the country's wider scientific community and to prove that the matter was nothing but an isolated incident, would continue to finance reforms.

\section{Debasish Debnath}

Department of Surgery, Medical School, University of Aberdeen, Foresterhill,

Aberdeen AB25 2ZD, UK

\section{Gulf Stream safe if wind blows and Earth turns}

Sir - Your News story "Gulf Stream probed for early warnings of system failure" (Nature 427, 769; 2004) discusses what the climate in the south of England would be like "without the Gulf Stream". Sadly, this phrase has been seen far too often, usually in newspapers concerned with the unlikely possibility of a new ice age in Britain triggered by the loss of the Gulf Stream.

European readers should be reassured that the Gulf Stream's existence is a consequence of the large-scale wind system over the North Atlantic Ocean, and of the nature of fluid motion on a rotating planet. The only way to produce an ocean circulation without a Gulf Stream is either to turn off the wind system, or to stop the Earth's rotation, or both.

Real questions exist about conceivable changes in the ocean circulation and its climate consequences. However, such discussions are not helped by hyperbole and alarmism. The occurrence of a climate state without the Gulf Stream any time soon - within tens of millions of years has a probability of little more than zero. Carl Wunsch

Earth, Atmospheric and Planetary Sciences, Massachusetts Institute of Technology, 77 Massachusetts Avenue, Cambridge, Massachusetts 02139, USA

\section{Poet described stars in Milky Way before Galileo}

Sir - It is commonly accepted that Galileo in 1609 was the first to appreciate the discrete nature of the stars in the Milky Way, by training his telescope on that part of the heavens. Your review of Francesco Bertola's book Via Lactea (Nature 427, 489; 2003) notes Bertola's suggestion that the true nature of the Milky Way may have been known before Galileo's observation.

There is evidence to support this view. Sonnet 31 of Thomas Watson's Hekatompathia (1582) describes the Milky Way as being composed of a huge number of discrete stars: "That can not tell how many starres appeare/ In part of heav'n, which Galaxia hight" - "Galaxia" is identified as the Milky Way in the notes to the poem. Sonnet 31 also appears in an earlier version of the Hekatompathia called Looking glase for Loouers. Watson, it seems, knew of the discrete nature of the stars before 1582 .

Sebastian Verro also describes the Milky Way as a collection of discrete stars in his 1581 Physicorum Libri X, Book II, chapter 17, page 31: "We now refer to the glorious Galaxia, which is also called the Milky Way. It is a chaos of minute, brightly shining stars, as if a fog or mist, which traverses the sky in an oblique path" (our translation).

Perhaps Watson and Verro gained their knowledge of the Milky Way through the use of earlier instruments than Galileo's telescope, such as the perspective glasses of the sixteenth-century English natural scientists Leonard and Thomas Digges. Eric Lewin Altschuler ${ }^{\star}$, William Jansen $\dagger$ ${ }^{*}$ Mount Sinai School of Medicine, 1425 Madison Avenue, Box 1240, New York, New York 10029, USA $\dagger 2611$ 18th Ave (G), Forest Grove, Oregon 97116, USA 